\title{
Cyclophosphamide-Topotecan Regimen
}

National Cancer Institute

\section{Source}

National Cancer Institute. Cyclophosphamide-Topotecan Regimen. NCI Thesaurus. Code C67233.

A regimen consisting of cyclophosphamide and topotecan, used for the treatment of recurrent or refractory childhood Ewing's sarcoma. 